\title{
Adolescent Alexithymia Research: Indigenous Sample Compared to Hispanic Sample in Southern Chile
}

\author{
Sebastian Guevara Kamm1, Enrique Sepulveda2 ${ }^{2}$ Burkhard Brosig1 \\ ${ }^{1}$ Center of General Pediatrics and Neonatology, Familial and Children's Psychosomatics, School of Medicine, \\ University of Giessen, Gießen, Germany \\ ${ }^{2}$ Department of Psychiatry, School of Medicine, University of Chile, Santiago, Chile \\ Email: sebastian.guevara@psycho.med.uni-giessen.de
}

Received 17 May 2016; accepted 28 June 2016; published 1 July 2016

Copyright (C) 2016 by authors and Scientific Research Publishing Inc.

This work is licensed under the Creative Commons Attribution International License (CC BY). http://creativecommons.org/licenses/by/4.0/

(c) (i) Open Access

\begin{abstract}
Toronto Alexithymia Scale (TAS-20) adolescent research became increasingly popular. We found no data examining two different ethnical adolescent groups sharing comparable environment. Furthermore, there are no indications that TAS-20 has ever been used in Chile. We conducted a transcultural comparison investigating the influence of ethnicity, gender and age on a low socioeconomic teenage population. Additionally, Confirmatory Factor Analysis (CFA) was performed. In this cohort study $(\mathrm{n}=\mathbf{2 2 5}), 95$ indigenous students were compared to the Hispanic control group of 130 participants. We found proper replicability and internal reliability of TAS-20 and the threefactor solution for our sample. We measured high alexithymia rates and significant differences between the ethnicities and genders but there was no influence of age. Although factor 3 (EOT) was inconsistent to some degree, TAS-20 resulted to be an appropriate measure for Chilean adolescents. Indigenous ethnicity, gender, low socioeconomic status, and power distance in a rural environment contribute to high alexithymia.
\end{abstract}

\section{Keywords}

Alexithymia, TAS-20, Chile, Adolescent, Cross-Cultural

\section{Introduction}

The term alexithymia expresses the incapacity to perceive and attribute feelings properly paired with the absence of verbal repertoire regarding moods. This multidimensional cognitive construct was firstly introduced during 
the early 1970s by Sifneos, when he described emotional deficits of psychiatric patients (Sifneos, 1973). According to our researches, this was the first time TAS-20 was used in Chile. The two ethnicities examined are expected to both show high total scores as consequence of poverty and high distance to power and further more to differ significantly in TAS-20 scoring. This article also demonstrates the cross-cultural validity of TAS-20 and its utilization on poor Chilean adolescent populations. There are other studies researching the influence of high distance to power on emotional behavior and cognition, but unlike other studies we compare two different ethnical and non-clinical populations that share comparable almost equal environment under supervised conditions. There are several factors influencing alexithymia in our sample, and this article investigates the influence of age, gender, sociodemography and culture.

\section{Chilean Population Structure Presupposes to Alexithymia}

Chilean citizens have suffered from collectivistic communist regime to right wing-dictatorship finally coming to democracy in 1989. In Latin-America Chile has almost the highest income level per capita (Foreign Ministry of Germany, 2012). Economically first-world rating is awaited. The U.N. considers Chile's development as "High Human Development" (UNDP, 2009). Nevertheless income disparities remain. Half of the population is centralized in the capital. The society is considered catholic, high power distant, and predominately masculine. As in many first world societies, the growth rate of Chile has decayed to $1.25 \%$. Fecundity rates are at 1.89 children, mortality is decreasing and age related dysfunctions are increasing (Acuna, Pérez, Villalón, \& Villalón, 2010; Damiánovic, Villalon, Espinosa, Ghio, \& Pavez, 2008). As for the masculine predominated society, women hold $54 \%$ of the total work and $95 \%$ of unremunerated domestic work. High salary gaps between the sexes have been found to persist in all occupational sectors (Bravo, 2004; INE, 2009). For female citizens the prediction is that their main goals will be for them to be considered daughters during childhood, to become scholars in the early life stages, to give birth to own children; then to dedicate themselves to unremunerated domestic work and to take care of social and health related familial aspects. For males it is officially expected after childhood at first, to become students; college students then take the role as patriarchs of the family and eventually convert to remunerated workers. Between the ages of 15 - 19, gender differences already come to notice. $10 \%$ of the girls work in remunerated jobs whereas $17 \%$ of the boys work respectively. $14 \%$ of the girls within the same age range work unremunerated at home whereas only $5 \%$ of the boys attend unremunerated domestic duties (Bravo, 2004).

Already at school high power distance is notable. The education system is rigid. Teachers are considered to be of major importance and are treated with distance and utmost respect. An inspector controls students' appearance as soon as they enter the school. They inspect school uniforms, nails and facial hair; beard shaving is an obligation. In the classroom the students rise when any teacher or adult enters the room until they are authorized to sit. Classroom separation by sex is also a common practice. Sometimes classrooms are divided in half; one side is for boys the other side for girls. It is also common procedure to only operate sex-separated schools. Most facilities have late schedules and some even offer residential services. It seems to be apparent that due to the amount of time students spend in their schools those facilities have notable influence in the children's development.

The majority of Chilean population is Hispanic and mestizo, about $4.6 \%$ is considered indigenous. The examined Mapuche tribe which is counting $\mathbf{8 7 . 3 \%}$ of all indigenous citizens is the largest tribe (CONADI, 2010). Aside from the main population, which suffers from injustice and high power distance, the indigenous people also suffer severe oppression. The Mapuche concept of sickness consists of bodily aspects of sickness paired with a spiritual cause (Pérez Sales, Durán Pérez, \& Bacic Herzfeld, 2005). In a cross-cultural study of pain, Perez Sales further examines the Mapuche participants. Grief as a psychological entity is not well recognized. In Mapuche common believe feelings such as grief lead to bodily aspects of sickness. The Mapuche's traditional way of perceiving of intrapsychic matters indicates a lack of emotional processing, at least if modern psychiatric standards are applied (Pérez Sales \& Lucena, 2000).

To summarize, the goal of this study was the almost equal environment the students were exposed to, the supervised performance and the application of CFA in order to address two important yet unresolved issues concerning alexithymia: (1) is there an ethnical influence on alexithymia that goes beyond socioeconomic variables in a non-clinical sample; and (2) is the measure appropriate for Chilean adolescents. 


\section{Materials and Methods}

\subsection{Sample}

Our Study investigates two different ethnical adolescent groups (Hispanic and Indigenous) sharing comparable socioeconomic, residential and educational environment. The selection of the area was effected by advice of state indigenous organization CONADI in $9^{\text {th }}$ Araucania-Region of southern Chile. Over $62.5 \%$ of the students that were examined are officially considered to be threatened by social vulnerability and also categorized as low-socioeconomic by Chilean government (SIMCE \& Gobierno de Chile, 2010). Average total familial income rates in all of the three examined schools are 350 USD per month. Each school is sex mixed. 225 pupils participated in this study. $55.3 \%$ were female $44.2 \%$ male participants. The students' ages ranged from 13 to 20 years old with an agglomeration of $86.2 \%$ between 14 and 17 years. The average age was 15.5 years. $42.2 \%$ were categorized Indigenous and 57.8\% Hispanic. Ethnical separation of results was effected by a Mapuche tribe member. The tests were separated correspondent to the ethnical provenance of each surname. In Chile surnames, by law, must carry first surname of the father and first surname of the mother respectively. All participants carrying one or two indigenous surnames were considered indigenous and placed in indigenous group. All remaining Hispanic participants were allocated in the Hispanic control group. All adolescents participating in this study were able to understand and write Spanish language. The study was effected under knowledge and support of the local education departments, mayors, school directors, teachers and state organization CONADI. The students' freewill was respected and participation was voluntarily. However, all pupils participated.

\subsection{Measures}

Alexithymia was measured by TAS-20 which is the most widely and also most carefully validated tool until today. Its test-retest reliability, internal consistency and discriminant, convergent, concurrent and factorial validity have been considered to be good (Bagby, Parker, \& Taylor, 1994; Bagby, Taylor, \& Parker, 1994; Parker, Endler, Schmitz, Bagby, \& Taylor, 1993). Its proper cross cultural use has been proved in several studies (Paez, Martinez Sanchez, \& Velasco, 1999; Taylor, Bagby, \& Parker, 2003). We used the most common Spanish TAS-20 version which validity is also known to be good (Taylor et al., 2003; Martinez Sanchez, 1996). To assess prevalence of alexithymia we used cutoff point of $\geq 61$. The scale shows a three-factor structure that matches with the construct of alexithymia. Factor 1 assesses the difficulties in identifying feelings and differentiate them from physical sensations which accompany emotional tensions (DIF); Factor 2 assesses difficulties in describing feelings to others (DDF); Factor 3 assesses an externally oriented way of thinking (EOT). The threefactor structure is most commonly applied and superior to one, two or four-factor structure (Taylor, Parker, \& Bagby, 2003; Popp et al., 2008). It could be replicated in several highly diverse cultures and thus constitutes the best factor-structure to be used for cross-cultural research (Taylor et al., 2003).

\subsection{Procedure}

The tests were effected during regular school schedule. Teachers were informed on short notice of the performance. Teachers and staff involved in this study entered the classroom together and the students were instructed regarding the execution of the tests. They were then informed about the purpose of the tests, which was described as measurement of their feelings and expressions. The participants were notified that the collected data was treated strictly anonymously and that neither their teachers and parents nor the school authorities or local departments would be informed about the outcome in a personalized way. The participation was completely voluntary. The participants then filled out the forms under supervision of staff and their teachers.

\subsection{Statistical Methods}

The Data was analyzed using the SPSS Statistics Version 21. TAS total score and subscale scores were compared between the sexes and the ethnic groups by use of student t-test. The Shapiro Wilk Test indicated that the population was normally distributed. Scores of ethnic groups were also compared by one-way analysis of variance (ANOVA). In order to compare different groups we separated per sex, age, school class, ethnicity and subscales. The sample was considered large enough to sub classify groups (Taylor et al., 2003). Correlation between the groups was effected per Pearson. For between-group comparisons we additionally conducted Pear- 
son's chi-square test. We selected the three factor model solution consisting of DIF, DDF and EOT. A translation error in item 12 was located afterwards. As recommended by the developer of the scale, CFA is the desirable approach for testing the validity of the TAS-20 in different populations and considered as a valid tool for cross-cultural research (Taylor et al., 2003). In order to assure the measure was accurate for Chilean population CFA was conducted using SPSS Amos Version 20. We used several indices to evaluate the Goodness-of-Fit of the proposed model. Each indice has its particular strength and weaknesses: the goodness-of-fit index (GFI: a score $>0.85$ ), the adjusted goodness-of-fit index (AGFI: a score $>0.80$ ) and the root-mean-square-error-ofapproximation (RMSEA: a score $<0.08$ ). We also used the ratio of the chi-square to its degrees of freedom $(\chi 2 / \mathrm{df}$ ratio), with a criterion of a value $<5$ and preferable $<2$. The sample also resulted large enough to perform CFA (Marsh, Balla, \& McDonald, 1988).

\section{Results}

\subsection{Confirmatory Factor Analysis}

The parameter estimates from the CFA and correlations for the relationships among the three factors are demonstrated in Table 1. Between factors 1 and 2 the estimates were significant $(p<0.01)$ for the sample. Between

Table 1. Parameter estimates of factor loadings and factor correlations.

\begin{tabular}{|c|c|}
\hline Item & Parameter Estimates \\
\hline \multicolumn{2}{|c|}{ Difficulty Identifying Feelings (DIF) } \\
\hline 1. & 0.59 \\
\hline 3. & 0.40 \\
\hline 6. & 0.50 \\
\hline 7. & 0.59 \\
\hline 9. & 0.60 \\
\hline 13. & 0.59 \\
\hline 14. & 0.51 \\
\hline \multicolumn{2}{|c|}{ Difficulty Describing Feelings (DDF) } \\
\hline 2. & 0.65 \\
\hline 4. & 0.27 \\
\hline 11. & 0.35 \\
\hline 12. & 0.18 \\
\hline 17. & 0.45 \\
\hline \multicolumn{2}{|c|}{ Externally Oriented Thinking (EOT) } \\
\hline 5. & 0.41 \\
\hline 8. & 0.01 \\
\hline 10. & 0.39 \\
\hline 15. & 0.16 \\
\hline 16. & 0.35 \\
\hline 18. & 0.23 \\
\hline 19. & 0.45 \\
\hline 20. & 0.04 \\
\hline \multicolumn{2}{|c|}{ Factor Correlations } \\
\hline DIF*DDF & $0.84 * * *$ \\
\hline DIF*EOT & 0.05 \\
\hline EOT*DDF & 0.02 \\
\hline
\end{tabular}

\footnotetext{
${ }^{\mathrm{a}}=$ accepted value, $* * * P \leq 0.01$.
} 
factors 1 and 3 and between Factors 2 and 3 relationships were not significant. The measures of fit GFI $=0.915$, AGFI $=0.89$, RMSEA $=0.039$ are presented in Table 2 . The chi square/df ratio was $<2$.

\subsection{Descriptive Statistics}

The mean total score of TAS-20 was (60.95, SD: 10.80). The mean score for Hispanic sample was (59.35, SD: 11.09) and for the indigenous sample (63.14, SD: 10.04) as demonstrated in Table 3 . The mean score variation between both ethnical samples was significant $(p<0.01)$. The mean score for factor DIF was (22.08, SD: 6.77) for the Hispanic and (24.01, SD: 5.74) for the Indigenous sample. The score difference was significant $(p<$ 0.05). Regarding Factor DDF score difference was significant $(p<0.05)$, mean score was (15.69, SD: 4.14) for the Hispanic and (16.62, SD: 3.97) for the Indigenous sample. Referring to factor EOT scores were (21.66, SD: 4.56) and (22.70, SD: 3.69) respectively also with a significant ethnical difference $(p<0.05)$.

When cut-off score was applied to the total TAS-20 score, ethnical differences remained significant $(p<0.05)$ as presented in Table $4.56 .0 \%$ of the total sample can be considered alexithymic. Separated in ethnicities, $50.0 \%$ of the Hispanic sample and $64.2 \%$ of Indigenous sample can be considered alexithymic. Figure 1 displays a graphic interpretation between the ethnicities.

Table 2. Measures of fit (CFA).

\begin{tabular}{ccccc}
\hline Chi-Square Test (df: 167$)$ & $(\chi 2 /$ df Ratio) & $($ GFI $)$ & $($ AGFI) & (RMSEA) \\
\hline $223.56^{\mathrm{a}}$ & $1.34^{\mathrm{a}}$ & $0.915^{\mathrm{a}}$ & $0.89^{\mathrm{a}}$ & $0.039^{\mathrm{a}}$ \\
\hline
\end{tabular}

RMSEA = Root-mean-square error of approximation, AGFI = Adjusted goodness-of-fit, GFI = Goodness-of-fit, ${ }^{\mathrm{a}}=$ Accepted value.

Table 3. Descriptive Statistics regarding Ethnicity.

\begin{tabular}{ccccccccccccc}
\hline & \multicolumn{3}{c}{ All subjects } & \multicolumn{3}{c}{ Hispanic } & \multicolumn{3}{c}{ Indigenous } \\
\hline TAS 20 & $\mathrm{n}$ & Mean & SD & $\mathrm{n}$ & Mean & SD & $\mathrm{n}$ & Mean & SD & $P$ \\
\hline TAS Factor 1 (DIF) & 227 & 22.90 & 6.41 & 130.00 & 22.08 & 6.77 & 97.00 & 24.01 & 5.74 & $<0.05$ \\
TAS Factor 2 (DDF & 230 & 16.09 & 4.08 & 132.00 & 15.69 & 4.14 & 98.00 & 16.62 & 3.97 & $<0.05$ \\
TAS Factor 3 (EOT) & 227 & 22.10 & 4.24 & 131.00 & 21.66 & 4.56 & 96.00 & 22.70 & 3.69 & $<0.05$ \\
TAS Total Score & 225 & 60.95 & 10.80 & 130.00 & 59.35 & 11.09 & 95.00 & 63.14 & 10.04 & $<0.01$ \\
\hline
\end{tabular}

DIF: Difficulties Identifying Feelings, DDF: Difficulties Describing Feelings, EOT: Externally-Oriented-Thinking.

Table 4. Alexithymia distribution by Ethnicity (With Cut Off).

\begin{tabular}{ccccccccccccc}
\hline & \multicolumn{3}{c}{ All Subjects } & \multicolumn{3}{c}{ Hispanic } & & & \multicolumn{2}{c}{ Indigenous } \\
\hline Variable & $\mathrm{n}$ & Quantity & $\%$ of $\mathrm{n}$ & $\mathrm{n}$ & Quantity & $\%$ of $\mathrm{n}$ & $\mathrm{n}$ & Quantity & $\%$ of $\mathrm{n}$ & $P$ \\
\hline Alexithymia & 225 & 126 & 56 & 130 & 65 & 50 & 95 & 61 & 64.2 & $<0.05$ \\
\hline
\end{tabular}

not alexithymic alexithymic

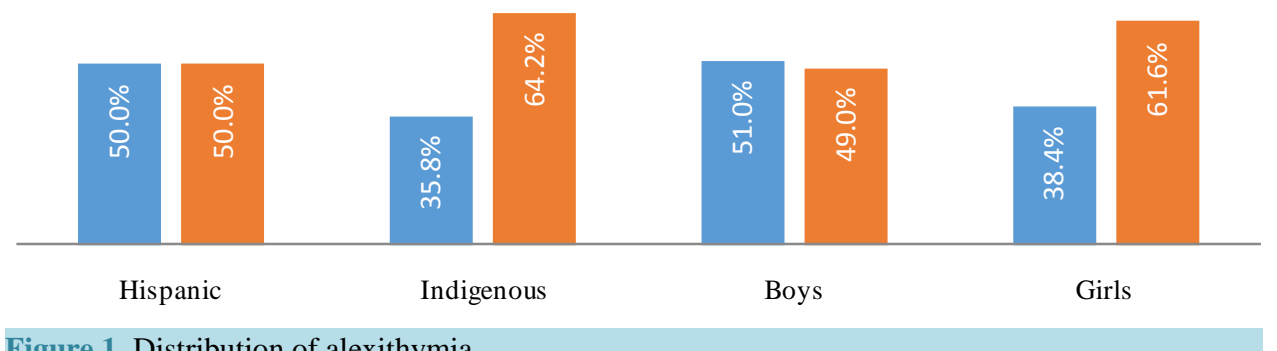

Figure 1. Distribution of alexithymia. 


\subsection{Group Statistics}

In this study gender difference in factor 1 (DIF) regarding to non-parametric correlation was statistically significant $(p<0.05)$. The mean score of girls $(23.38$, SD: 6.83) was higher than the mean score of the boys (22.31, SD: 5.83). Regarding factor 3 (EOT) both parametric and non-parametric statistics indicated that girls with (21.62, SD: 4.28) scored significantly lower $(p<0.05)$ on that scale than boys (22.7, SD: 4.13). Also in mean TAS-20 score and in DDF scale girls scored higher than boys as displayed in Table 5 , although differences were not considered significant. When cut-off was applied $61.6 \%$ of the girls and $49.0 \%$ of the boys can be considered alexithymic as presented in Figure 1, gender difference then did result significant $(p<0.05)$ as presented in Table 6.

We then revised the sample by ethnicities and again applied statistical procedure. $71.7 \%$ of the indigenous girls can be considered alexithymic whereas only $54.2 \%$ of the Hispanic girls were alexithymic as presented in Figure 2. Indigenous girls were $16.9 \%$ more alexithymic than indigenous boys. In the Hispanic control group girls were only $9.4 \%$ more alexithymic than boys.

\subsection{Age Distribution of Alexithymia}

We found no age influence on total TAS-20 score. The repartition of the most important age groups in our sample, the different TAS-20 mean scores of the same age groups and prevalence of alexithymia among the different

Table 5. Group Statistics regarding gender.

\begin{tabular}{|c|c|c|c|c|c|c|c|c|c|c|}
\hline \multirow[b]{2}{*}{ TAS 20} & \multicolumn{3}{|c|}{ All Subjects } & \multirow[b]{2}{*}{$\mathrm{n}$} & \multirow{2}{*}{$\begin{array}{l}\text { Girls } \\
\text { Mean }\end{array}$} & \multirow[b]{2}{*}{$\mathrm{SD}$} & \multicolumn{3}{|c|}{ Boys } & \multirow[b]{2}{*}{$P$} \\
\hline & $\mathrm{n}$ & Mean & $\mathrm{SD}$ & & & & $\mathrm{n}$ & Mean & SD & \\
\hline TAS Factor 1 (DIF) & 227 & 22.9 & 6.41 & 126 & 23.38 & 6.83 & 101 & 22.31 & 5.83 & $<0.05$ \\
\hline TAS Factor 2 (DDF) & 230 & 16.09 & 4.08 & 129 & 16.36 & 4.04 & 101 & 15.73 & 4.13 & \\
\hline TAS Factor 3 (EOT) & 227 & 22.1 & 4.24 & 127 & 21.62 & 4.28 & 100 & 22.7 & 4.13 & $<0.05$ \\
\hline TAS Total Score & 225 & 60.95 & 10.8 & 125 & 61.18 & 9.62 & 100 & 60.66 & 10.71 & \\
\hline
\end{tabular}

DIF: Difficulties Identifying Feelings, DDF: Difficulties Describing Feelings, EOT: Externally-Oriented-Thinking.

Table 6. Alexithymia distribution by gender (with cut off).

\begin{tabular}{|c|c|c|c|c|c|c|c|c|c|c|}
\hline \multirow[b]{2}{*}{ Variable } & \multirow[b]{2}{*}{$\mathrm{n}$} & \multirow{2}{*}{$\begin{array}{c}\text { All subjects } \\
\text { Quantity }\end{array}$} & \multicolumn{4}{|c|}{ Girls } & \multicolumn{4}{|c|}{ Boys } \\
\hline & & & $\%$ of $n$ & $\mathrm{n}$ & Quantity & $\%$ of $n$ & $\mathrm{n}$ & Quantity & $\%$ of $n$ & $P$ \\
\hline Alexithymia & 225 & 126 & 56 & 125 & 77 & 61.6 & 100 & 49 & 49 & $<0.05$ \\
\hline
\end{tabular}

匹 alexithymicboys -alexithymic girls

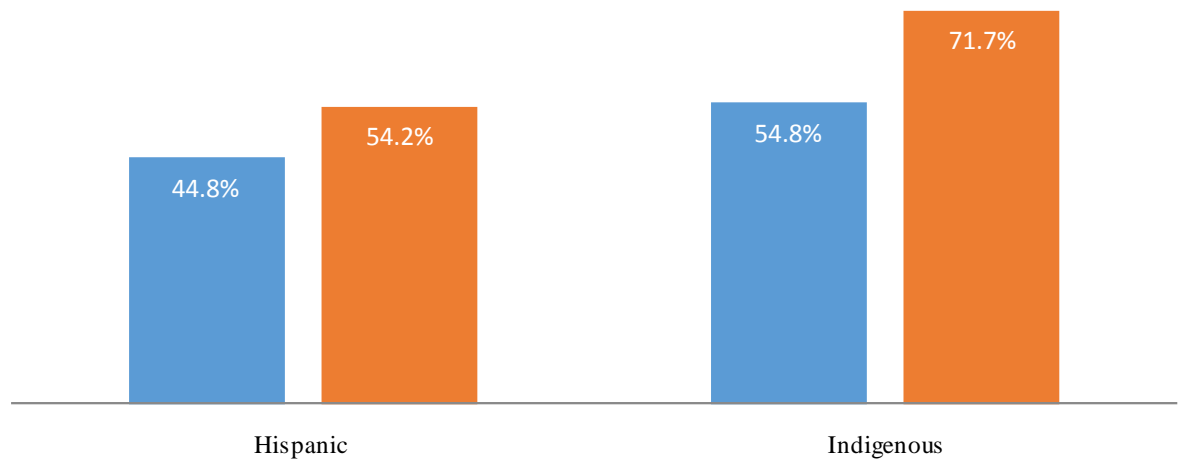

Figure 2. Gender gap by ethnicity. 
age groups are displayed in Figure 3 and Figure 4. Even when we applied cut-off we did not note any different tendencies. 16-year age group with $69.4 \%$ reached the highest TAS-20 score. While the 17-year age and 18-year age groups reached the lowest scores with $48.3 \%$ and $47.1 \%$ respectively.

\section{Discussion}

The overall findings of this study were the applicability of Spanish TAS-20 on a Chilean adolescent sample, the detection of high alexithymia scores and significant differences between the ethnicities and genders. Alexithymia can be associated to ethnicity, gender, disadvantageous and high power distant living conditions, but cannot be related to age.

The scores measured were considered high. The first aspect to examine is if the tool measures the characteristics of the syndrome accurately. CFA displays a good reliability and applicability of TAS-20 with regard to our sample. However we have to mention that some parameter estimates regarding EOT were unsatisfactory. Relationships between factors 1 and 3 and between Factors 2 and 3 were not significant which we ascribed to the inconsistencies regarding factor 3 . In literature, it has been well documented that deviations particularly pertain factor 3 of the original model (Bagby et al., 1994; Bagby et al., 1994). Nevertheless, inspection of the parameter estimates obtained from CFAs revealed that for several samples, the parameter estimates for one or more of the negatively keyed items on factor 3 were non-significant (Taylor et al., 2003). This is further supported by a more recent study which considers the 3-factor model the best solution even if inconsistencies appear (Meganck, Vanheule, \& Desme, 2008). Under these specific circumstances, lower factor loadings can be considered acceptable (Kline, 1994; Buehner, 2010). Particularly challenging was the result of item 12 (0.18) of DDF scale. Neither was that scale known to produce factor inconsistencies, nor was that factor negatively keyed. In the revision of the translation a serious error in the translation to Spanish was found making the item poorly comprehendible. The reversed translation was "The people ask me to explain with my feelings with more details".

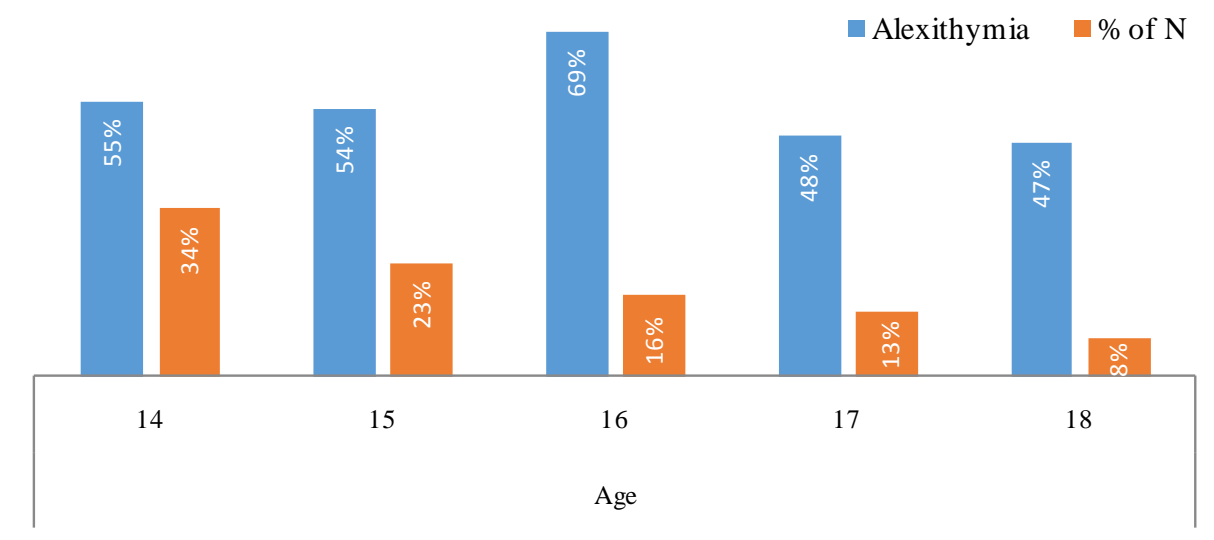

Figure 3. Alexithymia and age distribution.



Figure 4. TAS-20 means by age. 
The double use of the word "with" also made it hard for the Chilean part of our team to understand the meaning since the phrase was even less comprehensible in Spanish. Having assessed these specific particularities and taking into account that large sample sizes commonly influence fit indices as an artifact and that our sample size is $n=225$, our goodness of fit indices thus indicate a good support for the original three factor model.

TAS-20 became a reliable measurement instrument for adolescents (Valera \& Berenbaum, 2001; Sayar \& Topbas, 2005; Joukamaa et al., 2000; de Putte, Engelbert, Kuis, Kimpen, \& Uiterwaal, 2007; Guttman \& Laporte, 2002; Berenbaum, 1994; Zimmermann, 2006; Joukamaa et al., 2007; Lumley, Mader, Gramzow, \& Papineau, 1996; Yagi, Koyama, \& Fukunishi, 2003; Sakkinen, Kaltiala-Heino, Ranta, Haataja, \& Joukamaa, 2007; Honkalampi et al., 2009). However a Canadian study of J. Parker, one of the inventors of the scale indicates that the quality of measurement deteriorates progressively with younger age. An appropriate adaption of the item wordings for young adolescents and further validation is recommended (Parker, Eastabrook, Keefer, \& Wood, 2010). We came to opponent findings. The comparison of the study's results was undertaken. Firstly, our mean age was comparable. Thus such a comparison was considered valid. Interpretation of the results was challenging. In the Canadian study the inconsistencies were mainly ascribed to low reading capacity and complexness of the measure especially regarding factor 3 (Parker et al., 2010). But for Canadians semi-illiterate rates are generally considered high (ABC Literacy Foundation, 2005). Also the sample was containing clinical participants (e.g. inattention-hyperactivities; learning-disorders), which are likely to show even lower reading skills and more comorbidities influencing the measure. The author himself stated the psychometric problems encountered are likely to be exacerbated. $18.9 \%$ of the participants did not declare their ethnical background at all, leaving open to which extent other ethnicities were present and how good their reading skills were. $10.1 \%$ self identified as Asian, Aboriginal Canadian and "Others". Aboriginals and immigrants show higher functional illiteracy than "Caucasian white” Canadians (ABC Literacy Foundation, 2005). Our sample instead has been conducted in a school-based environment under almost perfect conditions, showing an average student skill level and ethnical background. Chile has the third lowest illiterate rate in Latin America (Alfalit, 2009). The national university entrance qualification test indicated that the participants of our study obtained language-results that were higher or slightly lower than the national average (DEMRE, 2012), similar results were obtained in a national reading proficiency test (Agencia de Calidad de la Educación, 2010). Inconsistencies in our study only regard factor 3 (EOT) whereas Parkers study also concerns factor 1 (DIF). Furthermore age had no effect on alexithymia, whereas in the Canadian study mean scores significantly increased with younger age. There are indications that the English TAS-20 version is more difficult to understand than the Spanish version due to the language coding (Pellegrino, Coupe, \& Marsico, 2011). We cannot say whether the original English version needs to be revised for young adolescents. Parker's findings however indicate that further research seems necessary.

Our study as most larger studies (Joukamaa et al., 2007; Kokkonen et al., 2001; Sakkinen et al., 2007) indicates no influence of age on alexithymia. In people from 30 to 90 years age might affect alxithymia (Mattila, Salminen, Nummi, \& Joukamaa, 2006) as an expression of personality changes in those live stages (Specht, Elgoff, \& Schmukle, 2011). Alexithymia peak at the age of 16 in our study indicates that during puberty personality associated skills are tried out and sophisticated often leading to troubling situations. The constant decrease of alexithymia in the older age groups of our sample indicates that during childhood abilities of recognition, comprehension of emotions as well as abstraction and reflection increase towards adolescence (Bajgar, Ciarrochi, \& Lane, 2005; Cotton, 2000).

We found several circumstances gathered that are known to contribute to development of alexithymia. Hispanic participants (Martinez Sanchez \& Costa Ball, 2013; Paez \& Vergara, 1995; Vahia \& Ng, 2013) with low socioeconomic status (Berenbaum, 1994; Joukamaa et al., 2007; Kauhanen, 1993; Kokkonen et al., 2001; Mattila et al., 2006; Mattila et al., 2007; Salminen, Saarijarvi, Aarela, Toikka, \& Kauhanen, 1999) and high power distance (Hofstede, 1991; Leff, 1977; Matsumoto, 1989; Paez et al., 1999) which are exposed to rigid parental, scholar and societal-structures that do restrict upward mobility and individualized open minded development. Teachers reported serious difficulties in communicating with the participants. Ethnicity has an effect on alexithymia. Both groups live under comparable environments but still the Indigenous group differs significantly in TAS-20 total score and all factors particularly in Factor 1 (DIF). It seems likely that power distance and oppression apply more to Indigenous participants (Bustos, 2010; El Mercurio, 2009; Mapuche Documentations Center, 2009). Particularly the perception of emotional signals is disturbed in those societies that are considered high power distant (Matsumoto, 1989; Paez et al., 1995; Paez et al., 1999). The mapuche people handle and perceive emotional matters differently in a more mystic way leading to deficient perception; evolvement of emotional 
processing seems disturbed (Pérez Sales et al., 2000; Pérez Sales et al., 2005). They use corporal expression and gestures to point out their feelings rather than to use an elaborated emotional language (Durán Pérez, 2000). This lack in verbal expression and identifying feelings accurately can be considered as a crucial part of the overall alexithymic concept which explains why the indigenous sample also scores significantly higher in factor 2 (DDF).

Women tend to express an important deficit when distinguishing feelings from corporal sensations, whereas men on the other hand, utilize internal physical sensations to determine their feelings. The outcome of this study shows concordant results. Girls scored significantly higher in (DIF) which indicates difficulties in identifying their feelings properly whereas boys scored significantly higher in EOT. The results share very close resemblances when compared to similar findings of several other studies (Kokkonen et al., 2001; Paez et al., 1999; Taylor et al., 2003). When contrasting the results for adolescent studies with those of the adult samples, it does not seem unusual that girls score higher in total alexithymia rating than boys (Joukamaa et al., 2007; Sakkinen et al., 2007; Sayar et al., 2005). Another reason for higher female scores might be the high power distance of the total sample. Strict roles and inequalities prevail and are often even expected or desired in high power distant societies which leads to higher (DIF) scores (Paez et al., 1999). It seems likely that religion and early sex-role divisions in patriarchal Chilean society are additionally triggered by low socioeconomic status. Also, it seems slightly peculiar that girls are concerned more sternly by familial and societal oppression and misuse, which would eventually affect their (DIF) scores. Gender differences were higher in the Indigenous group indicating power distance and cultural bias apply more abundantly to indigenous girls making them more susceptible.

High mean scores bring up the question regarding artifacts. Further research indicates a correlation between Alexithymia and Depression in Women (Mattila et al., 2006; Mattila et al., 2007). We have no indication that our results were affected by such a parameter. Our study had no clinical implications. Even though high alexithymia can be associated to other mental diseases such as Autism Spectrum Disorders (Szatmari et al., 2008), higher TAS-20 scores are more likely an effect of measuring negative affects rather than alexithymia itself (Marchesi \& De Panfilis, 2014). Gender differences in depression detection are most likely artefactual determinants of low symptoms thresholds in woman reporting the symptoms to the health system more often than men who tend to stoic values that influence their expression of feelings to others (Springer \& Mouzon, 2008; Piccinelli \& Wilkinson, 2000). The strength of this study certainly was its design, which concerned cohort sample selection, stable environmental factors and supervised conduction of the tests. All students participated. Nevertheless this study as with other cohort sample research publications, held several underlying limitations. Age range was small and socioeconomic status of all participants was very low. Assumptions to the general Chilean population are limited. The cut-off points are based on a study with a small adult sample and until today, they have not been validated for teenage populations. On the other hand, those cut-off points have never been seriously questioned and are applied in most of the studies. We decided to use those cut-off points in terms of comparability. Another limitation might be the way we chose our control group. Since the presence of two Hispanic surnames does not guarantee that the subject is not descending from Indigenous ethnicity to some extent, ethnical differences might be even higher. For instance it might be possible that a mestizo male with a first Hispanic surname of the father had children with mestizo women, carrying a second Hispanic surname of her mother. As consequence the child carried both Hispanic surnames but still featured a certain descent from the Mapuche tribe. The findings suggest that there is a lack of capacities of emotional processing and verbal repertoire in poor Indigenous and Hispanic students making mental diseases and emotional problems less expressible and detectable. Feelings and tenseness might outburst and lead to violent behavior (Manninen \& Joukamaa, 2011; Zimmermann, 2006); students of one school already revolted in the past and were detained by police force (Bustos, 2010; El Mercurio, 2009; Mapuche Documentations Center, 2009). There might be a correlation between the increase of violence and crime in Chile and alexithymia. Less power distant education, support for emotional conversations and assessment of the alexithymic situation should be integrated into the university’s prospective trainees' plans. Supervisors might instruct teachers to elaborate early emotional cognitive-behavioral based techniques and to reduce rigid power distant rules as inspector-controls, sex separation, standing up for teachers and adults and exchange those with more open-minded ones. A governmental rotation plan might help to exchange teachers and prospective teacher students from rural areas who might be alexithymic themselves to more urban ones and vice-versus. Reducing alexithymia might help to prevent late diagnosed diseases and lower follow up costs of public health and justice departments. 


\section{Acknowledgements}

We would like to announce our deepest gratitude towards Chile’s indigenous organization CONADI and to the participating mayors, principals, teachers and students of the public schools of Ercilla, Lumaco and DurandDurand. Without their most affectionate commitment this research would not have reached its aim.

\section{References}

ABC Literacy Foundation (2005). International Adult Literacy and Skills Survey (IALSS). Canada: ABC.

Acuna, E., Pérez, J. C., Villalón, J., \& Villalón, G. (2010). CHILE: Proyecciones y Estimaciones de Población . Total País 1950-2050. CEPAL, 208.

Agencia de Calidad de la Educación (2010). Resultados SIMCE cuarto basico y medio.

Alfalit (2009). Alfalit Chile Report. Alfalitchile.

Bagby, R. M., Parker, J. D. A., \& Taylor, G. J. (1994). The Twenty-Item Toronto Alexithymia Scale-I. Item Selection and Cross Validation of the Factor Structure. Journal of Psychosomatic Research, 38, 23-32. http://dx.doi.org/10.1016/0022-3999(94)90005-1

Bagby, R. M., Taylor, G. J., \& Parker, J. D. A. (1994). The Twenty-Item Toronto Alexithymia Scale-II. Convergent, Discriminant, and Concurrent Validity. Journal of Psychosomatic Research, 38, 33-40. http://dx.doi.org/10.1016/0022-3999(94)90006-X

Bajgar, J., Ciarrochi, J., Lane, R., \& Deane, F. P. (2005). Development of the Levels of Emotional Awareness Scale for Children (LEAS-C). British Journal of Developmental Psychology, 23, 569-586.

Berenbaum, J. J. T. (1994). Correlates and Retrospectively Reported Antecedents of Alexithymia. Psychosomatic Medicine, 56, 353-359. http://dx.doi.org/10.1097/00006842-199407000-00011

Bravo, R. (2004). Mujeres Chilenas-Tendencias en la última década. Chile: Servicio Nacional de la Mujer, SERNAM., Instituto Nacional de Estadísticas, INE.

Buehner, M. (2010). Einführung in die Test-Und Fragebogenkonstruktion. Pearson Deutschland GmbH, 371, $452,458$.

Bustos, R. (2010). Van seis atentados incendiarios este año en Malleco. La Nación.

CONADI (2010). Fondo de Desarrollo Indígena. CONADI Dirección Nacional Aldunate 285 Temuco.

Cotton, N. (2000). Normal Adolescence. In B. J. Kaplan, V. A. Sadock (Eds.), Comprehensive Textbook of Psychiatry (pp. 2551-2552). Baltimore: Lippincott Williams and Wilkins.

Damiánovic, N., Villalon, G., Espinosa, I., Ghio, G., \& Pavez, L. (2008). Population and Society—Demographic Aspects. Instituto Nacional de Estadísticas.

de Putte, E. M. V., Engelbert, R. H. H., Kuis, W., Kimpen, J. L. L., \& Uiterwaal, C. S. P. M. (2007). Alexithymia in Adolescents with Chronic Fatigue Syndrome. Journal of Psychosomatic Research, 63, 377-380.

DEMRE (2012). Promedio lenguage y comunicacion y matematica y pruenbas obligatorias y electivas.

Durán Pérez, T. et al. (2000). Muerte y Desaparición Forzada en la Araucanía: Una Aproximación Étnica KO’AGA ROÑE' ETA se.x. Derechos Online.

El Mercurio (2009). Ten Scholars Detained after Occupying School of Ercilla. http://www.emol.com/noticias/nacional/2009/07/30/369456/diez-alumnos-mapuches-fueron-detenidos-tras-tomarse-colegi o-en-ercilla.html

Foreign Ministry of Germany (2012). Chile-Rubrik Aussenpolitik des auswärtigen Amtes. Auswaertiges Amt Online.

Guttman, H., \& Laporte, L. (2002). Alexithymia, Empathy, and Psychological Symptoms in a Family Context. Comprehensive Psychiatry, 43, 448-455. http://dx.doi.org/10.1053/comp.2002.35905

Hofstede, G. (1991). Cultures and Organizations. Software of the Mind. London: McGraw Hill.

Honkalampi, K., Tolmunen, T., Hintikka, J., Rissanen, M. L., Kylma, J., \& Laukkanen, E. (2009). The Prevalence of Alexithymia and Its Relationship with Youth Self-Report Problem Scales among Finnish Adolescents. Comprehensive Psychiatry, 50, 263-268. http://dx.doi.org/10.1016/j.comppsych.2008.08.007

INE (2009). Ingresos de Hogares y Personas 2008. INE.

Joukamaa, M., Kokkonen, T., Veijola, J., Laksy, K., Karvonen, J. T., Jokelainen, J. et al. (2000). Alexithymia and Social Situation in Childhood. Journal of Psychosomatic Research, 48, 73.

Joukamaa, M., Taanila, A., Miettunen, J., Karvonen, J. T., Koskinen, M., \& Veijola, J. (2007). Epidemiology of Alexithymia among Adolescents. Journal of Psychosomatic Research, 63, 373-376. http://dx.doi.org/10.1016/j.jpsychores.2007.01.018 
Kauhanen, J. (1993). Dealing with Emotions and Health: A Population Study of Alexithymia in Middle-Aged Men. Kuopio: Publications D. Medical Sciences 25.

Kline, P. (1994). An Easy Guide to Factor Analysis. Abingdon-on-Thames: Routledge.

Kokkonen, P., Karvonen, J. T., Veijola, J., Laksy, K., Jokelainen, J., Jarvelin, M. R. et al. (2001). Prevalence and Sociodemographic Correlates of Alexithymia in a Population Sample of Young Adults. Comprehensive Psychiatry, 42, 471-476. http://dx.doi.org/10.1053/comp.2001.27892

Leff, J. (1977). The Cross-Cultural Study of Emotions. Culture, Medicine and Psychiatry, 1, 317-350. http://dx.doi.org/10.1007/BF00116242

Lumley, M. A., Mader, C., Gramzow, J., \& Papineau, K. (1996). Family Factors Related to Alexithymia Characteristics. Psychosomatic Medicine, 58, 211-216. http://dx.doi.org/10.1097/00006842-199605000-00003

Manninen, M., \& Joukamaa, M. (2011). Alexithymia Is Common among Adolescents with Severe Disruptive Behavior. The Journal of Nervous and Mental Disease, 199, 506-509. http://dx.doi.org/10.1097/NMD.0b013e3182214281

Mapuche Documentations Center (2009). Arrest of 16 Mapuche Scholars after Take of School of Ercilla. Mapuche Documentations Center.

Marchesi, C., Ossola, P., Tonna, M., \& De Panfilis, C. (2014). The TAS-20 More Likely Measures Negative Affects Rather than Alexithymia Itself in Patients with Major Depression, Panic Disorder, Eating Disorders and Substance Use Disorders. Comprehensive Psychiatry, 55, 972-978. http://dx.doi.org/10.1016/j.comppsych.2013.12.008

Marsh, H. W., Balla, J. R., \& McDonald, R. P. (1988). Goodness-of-Fit Indexes in Confirmatory Factor Analysis: The Effect of Sample Size. Psychological Bulletin, 103, 391-410.

Martinez Sanchez, F. (1996). The Spanish Version of the Toronto Alexithymia Scale (TAS-20). Clinica y Salud, 7, 19-32.

Martinez Sanchez, F., \& Costa Ball, C. (2013). Beliefs about the Effects of Social Sharing of Emotion in Alexithymia. Psicothema, 25, 179-184.

Matsumoto, D. (1989). Cultural Influences on the Perception of Emotion. Journal of Cross-Cultural Psychology, 20 , 92-105. http://dx.doi.org/10.1177/0022022189201006

Mattila, A. K., Ahola, K., Honkonen, T., Salminen, J. K., Huhtala, H., \& Joukamaa, M. (2007). Alexithymia and Occupational Burnout Are Strongly Associated in Working Population. Journal of Psychosomatic Research, 62, 657-665. http://dx.doi.org/10.1016/j.jpsychores.2007.01.002

Mattila, A. K., Salminen, J. K., Nummi, T., \& Joukamaa, M. (2006). Age Is Strongly Associated with Alexithymia in the General Population. Journal of Psychosomatic Research, 61, 629-635. http://dx.doi.org/10.1016/j.jpsychores.2006.04.013

Meganck, R., Vanheule, S., \& Desme, M. (2008). Factorial Validity and Measurement Invariance of the 20-Item Toronto Alexithymia Scale in Clinical and Nonclinical Samples. Assessment, 15, 36-47. http://dx.doi.org/10.1177/1073191107306140

Paez, D., \& Vergara, A. (1995). Culture Differences in Emotional Knowledge. In J. A. Russell, J.-M. Fernández-Dols, A. S. R. Manstead, \& J. C. Wellenkamp (Eds.), Everyday Conceptions of Emotion (pp. 415-434). Boston: Kluwer Academic. http://dx.doi.org/10.1007/978-94-015-8484-5_24

Paez, D., Martinez Sanchez, F., \& Velasco, C. (1999). Psychometric Validity of TAS-20: A Cross Cultural Study. Boletin de Psicologia, 63, 55-76.

Parker, J. D. A., Eastabrook, J. M., Keefer, K. V., \& Wood, L. M. (2010). Can Alexithymia Be Assessed in Adolescents? Psychometric Properties of the 20-Item Toronto Alexithymia Scale in Younger, Middle, and Older Adolescents. Psychological Assessment, 22, 798-808. http://dx.doi.org/10.1037/a0020256

Parker, J. D. A., Endler, N. S., Schmitz, P., Bagby, R. M., \& Taylor, G. J. (1993). Factorial Validity of the 20-Item Toronto Alexithymia Scale. European Journal of Personality, 7, 221-232. http://dx.doi.org/10.1002/per.2410070403

Pellegrino, F., Coupe, C., \& Marsico, E. (2011). A Cross Language Perspective on Speech Information Rate. Language, 87, 539-558. http://dx.doi.org/10.1353/lan.2011.0057

Pérez Sales, P., \& Lucena, R. (2000). Duelo: Una perspectiva transcultural. Mas alla del rito: La construccion social del sentimiento de dolor. Psiquiatría Pública, 12, 259-271.

Pérez Sales, P., Durán Pérez, T., \& Bacic Herzfeld, R. (2005). Muerte y Desaparición Forzada en la Araucanía: Una Aproximación Étnica. CEME Centro de estudiosMiguel Enríquez-Archivo Chile.

Piccinelli, M., \& Wilkinson, G. (2000). Gender Differences in Depression. The British Journal of Psychiatry, 177, 486-492.

Popp, K., Schäfer, R., Schneider, C., Brähler, E., Decker, O., Hardt, J. et al. (2008). Factor Structure and Reliability of the Toronto Alexithymia Scale (TAS-20) in the German Population. Psychosomatik Medizinische Psychologie, 58, 208-214.

Sakkinen, P., Kaltiala-Heino, R., Ranta, K., Haataja, R., \& Joukamaa, M. (2007). Psychometric Properties of the 20-Item Toronto Alexithymia Scale and Prevalence of Alexithymia in a Finnish Adolescent Population. Psychosomatics, 48, 154- 
161. http://dx.doi.org/10.1176/appi.psy.48.2.154

Salminen, J. K., Saarijarvi, S., Aarela, E., Toikka, T., \& Kauhanen, J. (1999). Prevalence of Alexithymia and Its Association with Sociodemographic Variables in the General Population of Finland. Journal of Psychosomatic Research, 46, 75-82. http://dx.doi.org/10.1016/S0022-3999(98)00053-1

Sayar, K., \& Topbas, M. (2005). Alexithymia and Dissociative Tendencies in an Adolescent Sample from Eastern Turkey. Psychiatry and Clinical Neurosciences, 59, 127-134. http://dx.doi.org/10.1111/j.1440-1819.2005.01346.x

Sifneos, P. (1973). The Prevalence of “Alexithymic” Characteristics in Psychosomatic Patients. Psychotherapy and Psychosomatics, 22, 255-262. http://dx.doi.org/10.1159/000286529

SIMCE, M. D. E., \& Gobierno de Chile (2010). SIMCE Antecedentes del Establecimiento. SIMCE-Ministerio De Educacion.

Specht, J., Elgoff, B., \& Schmukle, S. (2011). Stability and Change of Personality across the Life Course: The Impact of Age and Major Life Events on Mean-Level and Rank-Order Stability of the Big Five. Journal of Personality and Social Psychology, 101, 862-882. http://dx.doi.org/10.1037/a0024950

Springer, K. W., \& Mouzon, D. M. (2008). Masculinity and Health Care Seeking among Midlife Men: Variation by Social Context. MA Online.

Szatmari, P., Georgiades, S., Duku, E., Zwaigenbaum, L., Goldberg, J., \& Bennett, T. (2008). Alexithymia in Parents of Children with Autism Spectrum Disorder. Journal of Autism and Developmental Disorders, 38, 1859-1865. http://dx.doi.org/10.1007/s10803-008-0576-4

Taylor, G. J., Bagby, R. M., \& Parker, J. D. A. (2003). The 20-Item Toronto Alexithymia Scale-IV. Reliability and Factorial Validity in Different Languages and Cultures. Journal of Psychosomatic Research, 55, 277-283. http://dx.doi.org/10.1016/S0022-3999(02)00601-3

Taylor, G. J., Parker, J. D. A., \& Bagby, R. M. (2003). The 20-Item Toronto Alexithymia Scale III. Reliability and Factorial Validity in a Community Population. Journal of Psychosomatic Research, 55, 269-275. http://dx.doi.org/10.1016/S0022-3999(02)00578-0

UNDP (2009). Human Development Report 2009-Chile. Human Development Report Office.

Vahia, I. V., \& Ng, B. (2013). To What Factors Do Rural-Dwelling Hispanics Attribute DEPRESSIVE Symptoms? Depression Research and Treatment, 2013, Article ID: 781986. http://dx.doi.org/10.1155/2013/781986

Valera, E. M., \& Berenbaum, H. (2001). A Twin Study of Alexithymia. Psychotherapy and Psychosomatics, 70, $239-246$. http://dx.doi.org/10.1159/000056261

Yagi, Y., Koyama, K., \& Fukunishi, I. (2003). Intergenerational Association of Alexithymic Characteristics for College Students and Their Mothers. Journal of Psychosomatic Research, 55, 172. http://dx.doi.org/10.1016/s0022-3999(03)00277-0

Zimmermann, G. (2006). Delinquency in Male Adolescents: The Role of Alexithymia and Family Structure. Journal of Adolescence, 29, 321-332. http://dx.doi.org/10.1016/j.adolescence.2005.08.001

\section{Submit or recommend next manuscript to SCIRP and we will provide best service for you:}

Accepting pre-submission inquiries through Email, Facebook, Linkedin, Twitter, etc

A wide selection of journals (inclusive of 9 subjects, more than 200 journals)

Providing a 24-hour high-quality service

User-friendly online submission system

Fair and swift peer-review system

Efficient typesetting and proofreading procedure

Display of the result of downloads and visits, as well as the number of cited articles

Maximum dissemination of your research work

Submit your manuscript at: http://papersubmission.scirp.org/ 